\title{
A study on surface roughness of workpiece when grinding SKD11 and SUJ2 steels using $\mathrm{Al}_{2} \mathrm{O}_{3}$ and $\mathrm{CBN}$ wheels
}

\author{
Hoang Tien Dung ${ }^{1}$, Do Duc Trung ${ }^{1, *}$, Nguyen Van Thien ${ }^{1}$ and Le Hong Ky ${ }^{2}$ \\ ${ }^{1}$ Faculty of Mechanical Engineering, Hanoi University of Industry, No. 298, Cau Dien Street, Bac Tu Liem District, Hanoi, Vietnam \\ ${ }^{2}$ Vinh Long University of Technology Education, No. 73, Nguyen Hue Street, Ward 2, Vinh Long, Viet Nam
}

\begin{abstract}
This paper presents a study on surface roughness of workpiece when grinding SKD11, SUJ2 steels using $\mathrm{Al}_{2} \mathrm{O}_{3}$ and $\mathrm{CBN}$ grinding wheels. The method on modeling and predicting of surface roughness of workpiece in the grinding theoretical research was applied. However, when applying this method, it is necessary to identify the value of the roughness adjust factor in practical case. In this paper, this factor was found by experimental process when surface grinding SKD11 and SUJ2 steels by $\mathrm{Al}_{2} \mathrm{O}_{3}$ and $\mathrm{CBN}$ wheels. It helps values of calculating surface roughness to be similar to experimental datas.
\end{abstract}

\section{Introduction}

In grinding, the surface roughness of the workpiece surface is the most important element which may significantly impact the usefulness of the workpiece. Experimental research on surface roughness of workpiece in grinding has been done by many authors. Although the determination of empirical models is not complicated, their use is usually associated with fixed process conditions. As a result, the scope of empirical models is limited [2].

To overcome the above-mentioned problem, analytical models for surface roughness were tried out to predict the surface roughness at different grinding conditions [1,3-6].

An analytical model was developed for the prediction of the arithmetic mean surface roughness based on the probabilistic undeformed chip thickness model by R. L. Hecker and S. Liang [1]. This model uses ground finish as a function of the wheel microstructure, the process kinematic conditions and the material properties. The material properties and the wheel microstructure are considered in the surface roughness through the chip thickness model. A simple expression that relates the surface roughness with chip thickness was found, which was verified using experimental data from grinding. This method is simply, easy application and have referenced by many authors in recently years [7-8]. However, when applying this method, it is necessary to determine the value of the roughness adjust factor $(R)$ in practical case.

SKD11 and SUJ2 steels are types of popular alloy steel used in machine-building. This steel is popular in the manufacture of bearing, die mold and so on. In this work, experiment process has been done for surface grinding SKD11 and SUJ2 steels using $\mathrm{Al}_{2} \mathrm{O}_{3}$ and CBN wheels to get values of $R$ in paper of R. L. Hecker and S. Liang [1] in each case.

\section{Equation for predictive of surface roughness}

From analyzing of chip forming in grinding, R. L. Hecker and S. Liang [1] proposed the surface roughness equation:

Where:

$$
R_{a}=R \cdot 0,37 \cdot h_{m}
$$

$R$ is roughness adjust factor, it depends on certain condition.

$h_{m}$ is maximum of undeformed chip thickness. The existing chip thickness can be predicted as follows [9]:

$$
h_{m}=2 \sqrt{\frac{1}{N r} \frac{v_{w}}{v_{G}} \sqrt{\frac{t}{d_{e}}}}
$$

In which,

$v_{w}$ is workpiece velocity.

$v_{G}$ is grinding wheel velocity.

$t$ is depth of cut.

$d_{e}$ is equivalent to wheel diameter, and is determined by:

$$
\frac{1}{d_{e}}=\frac{1}{d_{G}} \pm \frac{1}{d_{W}}
$$

Where: $d_{G}$ and $d_{w}$ are the grinding wheel diameter and the workpiece diameter respectively.

$r$ is the ratio of the chip width to the thickness. In practice, it is difficult to determine the value of $r$ and it is assumed in the range of 10-20 [10]. In this paper, $r$ was assumed to be equal to 20 as in $[7,8,11]]$.

$N$ is the number of active grits per unit area; it can be predicted by the following equation [12]:

\footnotetext{
" Corresponding author: dotrung.th@gmail.com; doductrung@haui.edu.vn
} 


$$
N=4 f \frac{1}{d_{g}^{2}} \frac{1}{\sqrt[3]{\left(\frac{4 \pi}{3 \epsilon}\right)^{2}}}
$$

Where,

$f$ is the fraction of diamond particles involved in active grinding process; It is assumed that only one half of diamond particles is engaged in cutting and $f=0.5$ [12];

$d_{g}$ is the equivalent to spherical diameter of grit; $d_{g}$ is calculated by [13]:

$$
d_{g}=15.2 / M
$$

In which, $M$ is the mesh number used in the grading sieve; $\epsilon$ is volume fraction of grits in grinding wheel. In this study, the $\mathrm{Al}_{2} \mathrm{O}_{3}$ grinding wheels have a concentration of 100 and $\mathrm{CBN}$ grinding wheels have a concentration of 80 , or volume fraction $\epsilon=0.2[14]$ and $\epsilon=0.25[15]$ respectively.

Substituting the equations (2), (3), (4), (5) into (1) and after mathematical simplification, the value of the surface roughness can be determined by:

$R_{a}=$ R. $2,254 \cdot \frac{1}{\mathrm{M}} \cdot t^{1 / 4} \cdot\left(\frac{1}{f \cdot r}\right)^{1 / 2} \cdot\left(\frac{v_{W}}{v_{G}}\right)^{1 / 2}\left(\frac{4 \pi}{3 \epsilon}\right)^{1 / 3} \cdot\left(\frac{d_{G} \cdot d_{W}}{d_{G}+d_{W}}\right)^{1 / 4}$

\section{Determining the roughness adjust factor for some cases}

Experimental research was conducted on surface grinding SKD11 and SUJ2 steels, using $\mathrm{Al}_{2} \mathrm{O}_{3}$ and $\mathrm{CBN}$ grinding wheels. The surface roughness was measured by SJ301 surface roughness tester, were shown in figure 1 to 4 . Equation (6) was used to calculate surface roughness with some values of roughness adjust factor $(R)$, the calculating surface roughness was also shown in figure 1 to 4 .

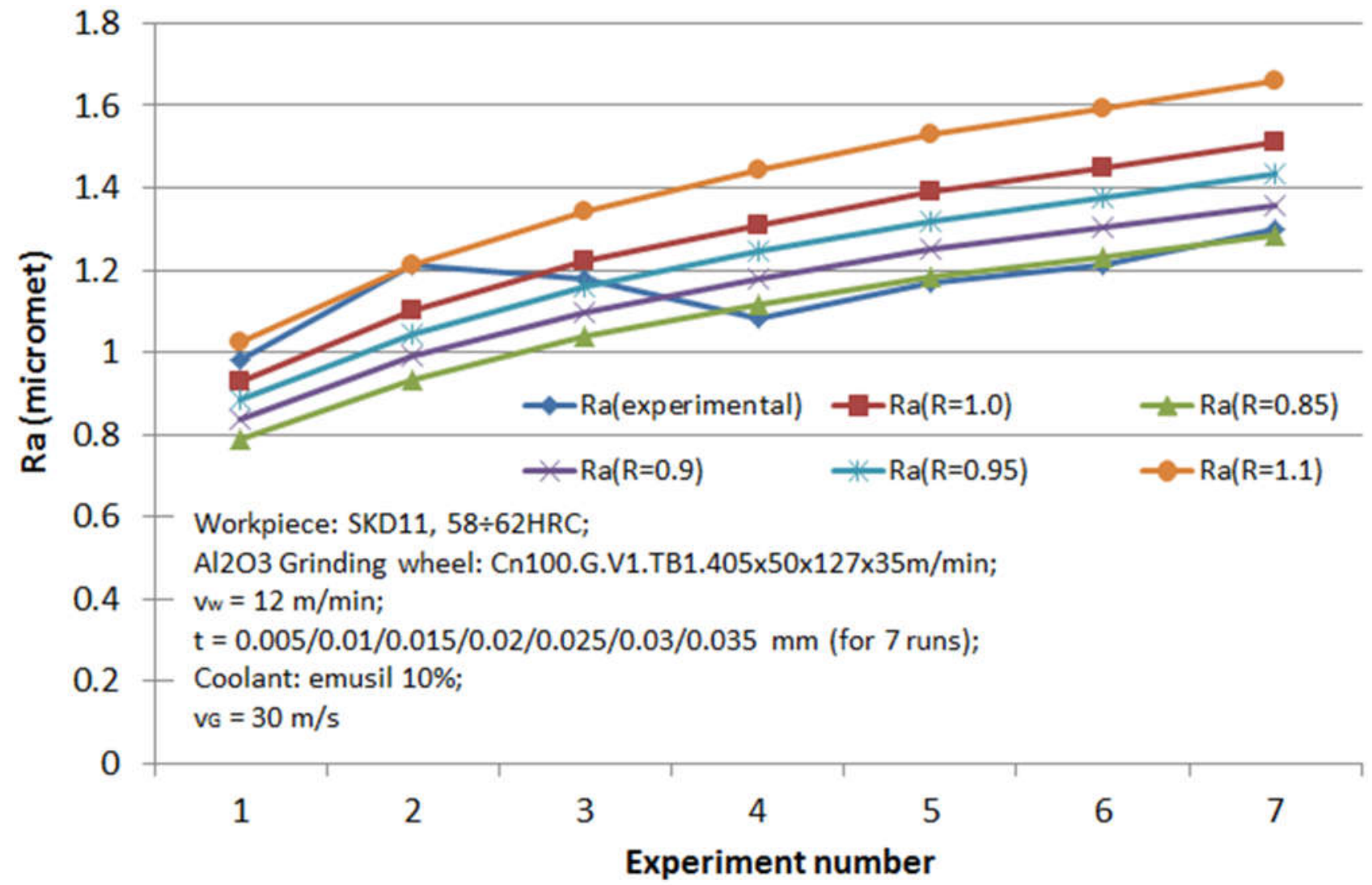

Fig. 1. $\mathrm{R}_{\mathrm{a}}$ Simulated and experimental data when grinding SKD11 steel using $\mathrm{Al}_{2} \mathrm{O}_{3}$ grinding wheel 


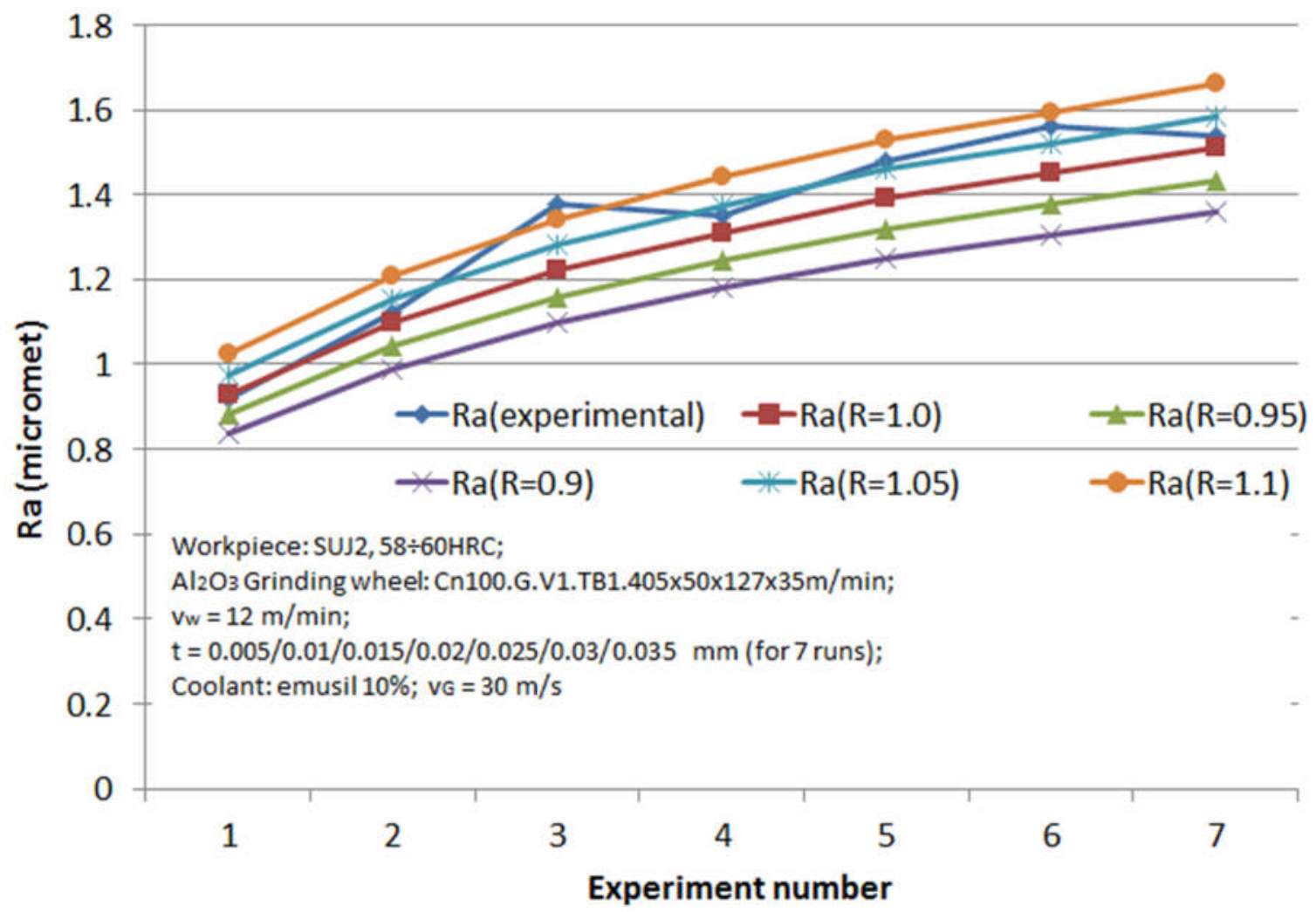

Fig. 2. $\mathrm{R}_{\mathrm{a}}$ Simulated and experimental data when grinding $\mathrm{SUJ} 2$ steel using $\mathrm{Al}_{2} \mathrm{O}_{3}$ grinding wheel

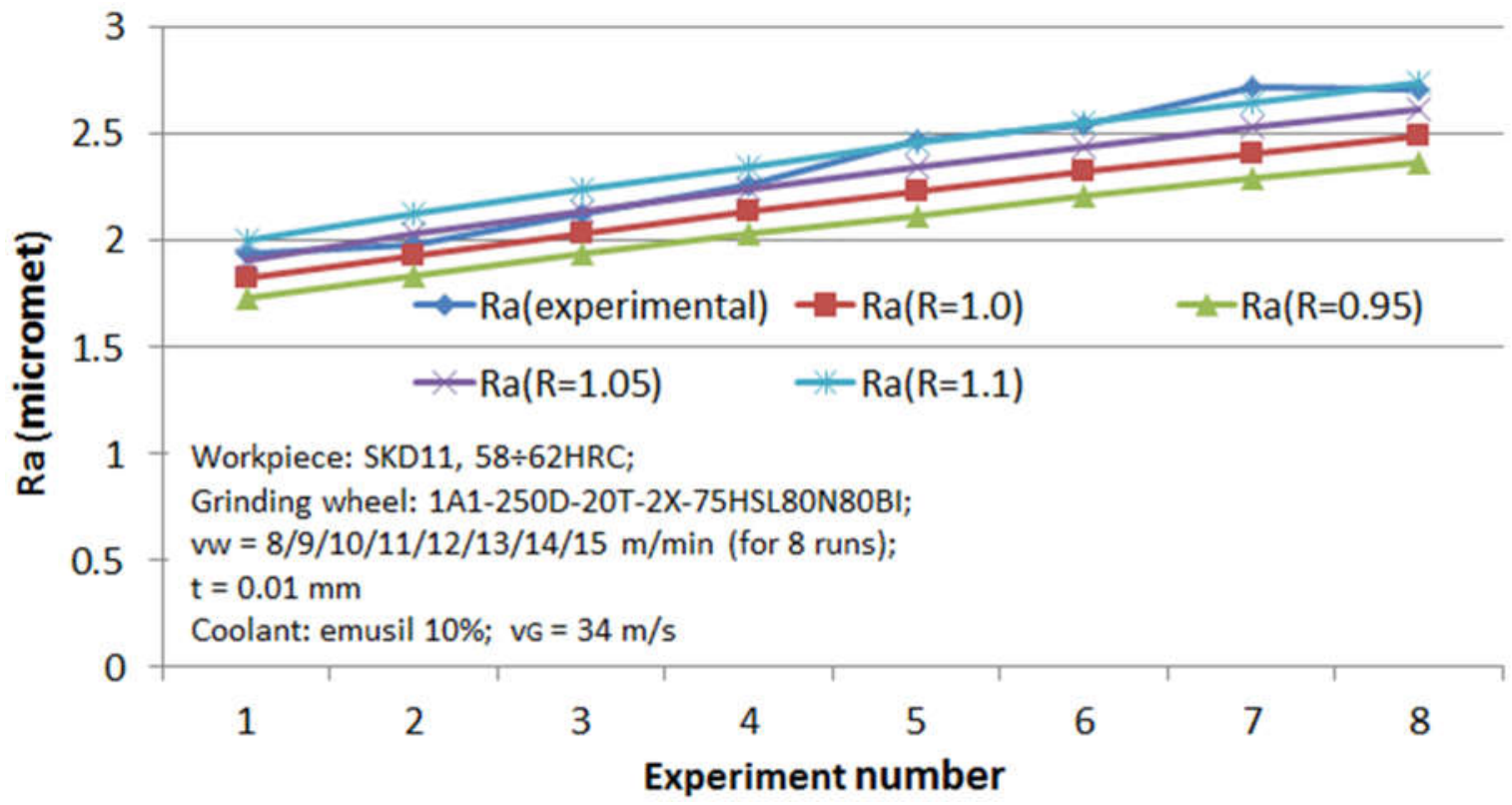

Fig. 3. $\mathrm{R}_{\mathrm{a}}$ Simulated and experimental data when grinding SKD11 steel using CBN grinding wheel 


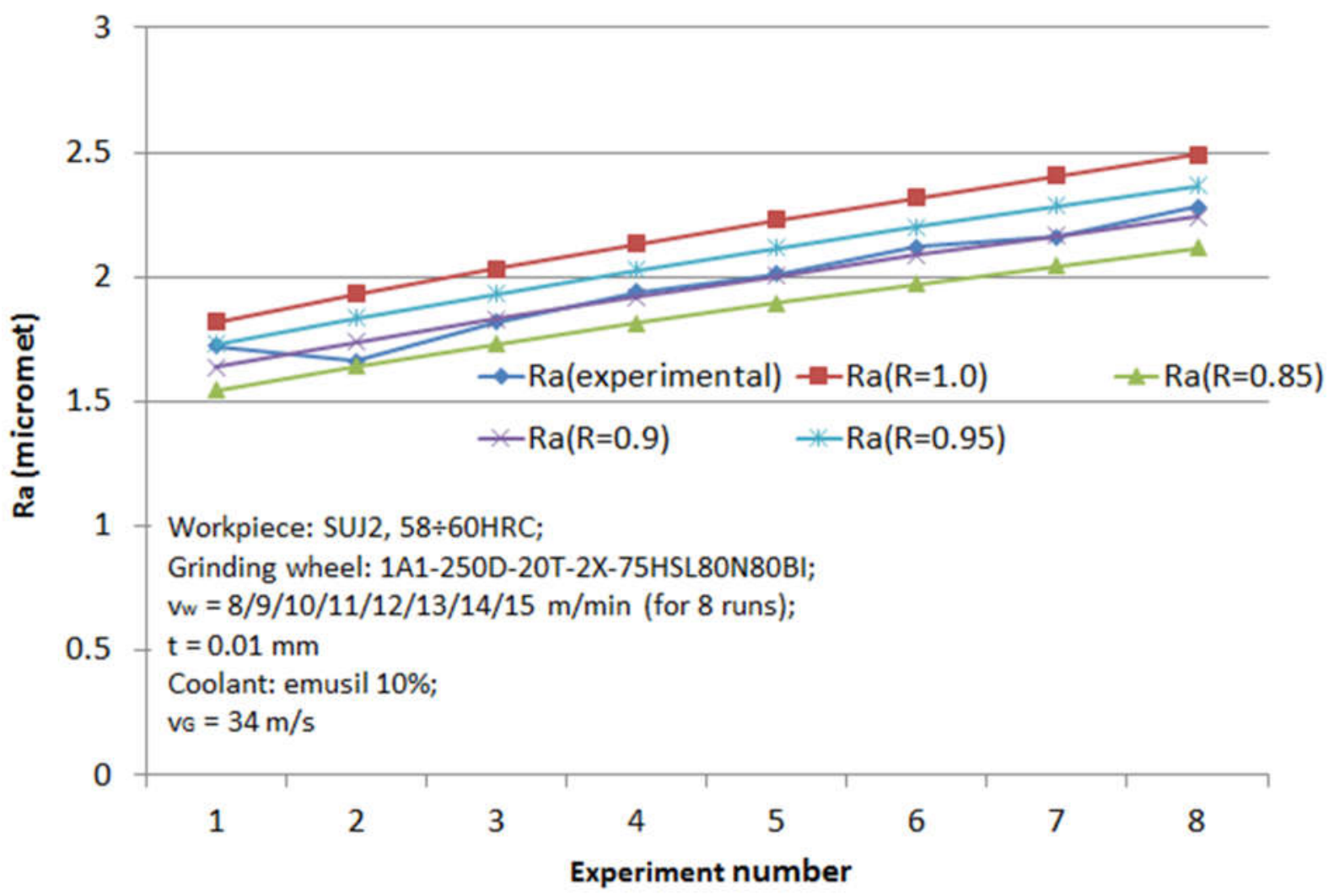

Fig. 4. $\mathrm{R}_{\mathrm{a}}$ Simulated and experimental data when grinding SUJ2 steel using CBN grinding wheel

From figures (1) to (4), some observations can be made as follows:

- To get the values of calculating surface roughness similar to the experimental surface roughness, it is necessary to choose value of $R$ in practical case.

- When grinding $\mathrm{SKD} 11$ by $\mathrm{Al}_{2} \mathrm{O}_{3}$ grinding wheel, value of $R$ depends on value of depth of cut. If $t=$ $0.005 \div 0.01$ then $R=1.1$; if $t=0.015$ then $R=$ 0.95 ; and if $t=0.02 \div 0.035$ then $R=0.85$.

- When grinding $\mathrm{SUJ} 2$ by $\mathrm{Al}_{2} \mathrm{O}_{3}$ grinding wheel ,if the value of $R$ was selected as $R=1 \div 1.05$, the value of calculating surface roughness is very similar to experimental datas, except when $t=0.015$ then $R=1.1$.

- When grinding SKD11 by CBN grinding wheel, $R=1.05$ if $v_{w}=8 \div 11 \mathrm{~m} / \mathrm{min} ;$ in case $v_{w}>$ $11 \mathrm{~m} / \mathrm{min}$ then $R=1.1$.

- When grinding SUJ2 by CBN grinding wheel, if $R=0.9$, the value of calculating surface roughness is in good agreement with experimental datas.

\section{Conclusions}

Simulating the grinding process to predict the surface roughness of workpiece in particular cases will help reduce the time spent on machine adjustment and trial processing, which will lead to processing cost reduction and the enhancement of the product quality. This paper shows values of roughness adjust factor when surface grinding SKD11 and SUJ2 steels by $\mathrm{Al}_{2} \mathrm{O}_{3}$ and $\mathrm{CBN}$ wheels. From this, values of calculating surface roughness are very similar to experimental data.

\section{References}

1. R. L. Hecker, S. Liang, Predictive modeling of surface roughness in grinding, International Journal of Machine Tools and Manufacture, 43, 755-761 (2003)

2. S. Malkin, C. Guo, Grinding technology - theory and applications of machining with abrasives - Second editor, Industrial Press, New Yourk (2008)

3. G. K. Lal, M. C. Shaw, The role of grain tip radius in finegrinding, Journal of Engineering for Industry August, 1119-1125 (1975)

4. Q. Cui, S. Chen, H. Ding, K. Cheng, Dynamic Model of Material Removal Process in Through - feed Grinding Based on the Lagrange Equation, Trans tech Publications, Switzwerland, 667, 173-180, (2016)

5. H. Tonshoff, J. Peters, I. Inasaki, T. Paul, Modeling and simulation of grinding processes, Annals of CIRP 41, 677-688 (1992)

6. K. Nakayama, M. C. Shaw, Study of finish produced in surface grinding, part 2, Proceeding of the Institution of Mechanical Engineers, 182, 179-194 (1968)

7. D. Duc Trung, N. Van Thien, H. Tien Dung, Predictive Surface Roughness of Workpiece in Surface Grinding, American Journal of Materials Research, 4, 37-41 (2017). 
8. D. Duc Trung, P. Xuan Son, Predictive surface roughness of workpiece in cylindrical grinding, The first internaltional conference on material, machines and methods for sustainable development, 2, 831-837 (2018)

9. A. Venu Gopal, V. Rao, A new chip-thickness model for performance assessment of silicon carbide grinding. Int $\mathrm{J}$ Adv Manuf Technol, 24, 816-820 (2004)

10. J. E. Mayer, G. P.Fang, Effect of grit depth of cut on strength of ground ceramics, Annals CIRP, 43, 309312 (1994)

11. S. Somasundaram, C.Thiagarajan, Experimental Evaluation of a Chip Thickness Model Based on the Fracture Toughness of Abrasive and Work Material in Grinding of Alumina Ceramics. International
Journal of Modern Engineering Research, 3, 38253829 (2013)

12. Xu. Hockin, S. Jahanmir, L. K. Ives, Effect of grinding on strength of tetragonal zirconia and zirconia-toughned alumina, Journal of Machining Science Technology, 1, 49-66 (1997)

13. Loan D. Marinescu, U. Eckart, W. Brian Rowe, Handbook of machining with grinding wheels, CRC Press Taylor \& Francis Group (2006)

14. X. Chen, Strategy for the selection of grinding wheel dressing conditions, Ph.D. Thesis, Liverpool John Moores University (1995)

15. Z .Ping, H. Michele, Grinding Wheel Condition Prediction and Improvement, Michigan Technological University, Houghton, MI (2002) 